\title{
Effect of feed restriction during calfhood on serum concentrations of metabolic hormones, gonadotropins, testosterone, and on sexual development in bulls
}

\author{
L F C Brito, A D Barth, N C Rawlings, R E Wilde ${ }^{1}$, D H Crews Jr ${ }^{1}$, Y R Boisclair ${ }^{2}$, R A Ehrhardt $^{2}$ \\ and J P Kastelic ${ }^{1}$ \\ Western College of Veterinary Medicine, University of Saskatchewan, 52 Campus Dr, Saskatoon, Saskatchewan, \\ Canada S7N 5B4, ' Lethbridge Research Centre, Agriculture and Agri-Food Canada, PO Box 3000, Lethbridge, \\ Alberta, Canada T1J 4B1 and ${ }^{2}$ Department of Animal Science, Cornell University, Ithaca, New York 14853, USA
}

Correspondence should be addressed to L F C Brito who is now at Department of Clinical Studies, University of Pennsylvania, New Bolton Center, 382 West Street Road, Kennett Square, Pennsylvania 19348, USA; Email: Ifcbrito@lycos.com

\begin{abstract}
The objective of the present study was to evaluate the effects of feed restriction during calfhood on serum concentrations of metabolic hormones, gonadotropins, and testosterone, and on sexual development in bulls. Eight beef bull calves received a control diet from 10 to 70 weeks of age. An additional 16 calves had restricted feed (75\% of control) from 10 to 26 weeks of age (calfhood), followed by either control or high nutrition ( $n=8$ /group) during the peripubertal period until 70 weeks of age. Restricted feed during calfhood inhibited the hypothalamic GnRH pulse generator, reduced the pituitary response to $\mathrm{GnRH}$, impaired testicular steroidogenesis, delayed puberty, and reduced testicular weight at 70 weeks of age, regardless of the nutrition during the peripubertal period.

Restricted feed reduced serum IGF-I concentrations, but concentrations of leptin, insulin, and GH were not affected. In conclusion, restricted feed during calfhood impaired sexual development in bulls due to adverse effects on every level of the hypothalamuspituitary-gonad axis and these effects were not overcome by supplemental feeding during the peripubertal period. Furthermore, based on temporal associations, the effects of restricted feed on the hypothalamus-pituitary-gonad axis might be mediated by serum IGF-I concentrations. These results supported the hypotheses that the pattern of LH secretion during the early gonadotropin rise during calfhood is the main determinant of age of puberty in bulls and that gonadotropin-independent mechanisms involved in testicular growth during the peripubertal period are affected by previous LH exposure.
\end{abstract}

Reproduction (2007) 134 171-181

\section{Introduction}

The hypothalamus dictates the timing of sexual development through gonadotrophin-releasing hormone $(\mathrm{GnRH})$ secretion in bulls. Circulating gonadotropin concentrations increase at 2-3 months of age in bulls (early gonadotropin rise), triggering the cellular events that lead to testicular growth and establishment of spermatogenesis (Rawlings et al. 1978, Amann \& Walker 1983). Luteinizing hormone $(\mathrm{LH})$ secretion during the period of the early gonadotropin rise seems to be the main determinant of age at puberty in bulls. Whereas increased LH pulse frequency and mean concentration during the early rise were associated with a reduced age at puberty (Evans et al. 1995, Aravindakshan et al. 2000), inhibiting LH secretion during the early gonadotropin rise delayed puberty in bulls (Chandolia et al. 1997b). In bulls, nutrition during calfhood had direct effects on the
$\mathrm{GnRH}$ pulse generator in the hypothalamus; low nutrition decreased LH secretion, whereas high nutrition increased secretion (Brito et al. 2007a, 2007b). Therefore, restricted feed during calfhood may affect the early gonadotropin rise and age at puberty in bulls, regardless of the nutrition provided after this critical period of development.

The portion of the central system involved in monitoring body metabolism and energy, the 'metabolic sensor', provides signals to the GnRH pulse generator in the hypothalamus and is a central link between nutrition and reproduction (Blache et al. 2002, 2003, Schneider 2004). The metabolic sensor translates signals provided by circulating (peripheral) concentrations of certain hormones into neuronal signs that ultimately regulate gonadotropin secretion. Identification of hormonal links between nutritional status and the metabolic sensor is 
essential for elucidation of the mechanisms by which nutrition affects reproduction. Metabolic hormones such as leptin, insulin, growth hormone $(\mathrm{GH})$, and insulin-like growth factor-I (IGF-I) are involved in controlling appetite and metabolism and may also be involved in regulating gonadotropin secretion. Temporal associations suggested that IGF-I might be involved in regulating $\mathrm{LH}$ secretion in bulls receiving varying levels of nutrition during calfhood (Brito et al. 2007a, 2007b).

After the period of the early gonadotropin rise, gonadotropin concentrations decreased and remained largely unchanged thereafter (Rawlings et al. 1978, Amann \& Walker 1983). However, testicular growth was accelerated from 6 to 16 months of age in bulls (peripubertal period; Coulter 1986, Barth \& Ominski 2000), indicating that gonadotropin-independent mechanisms are involved in regulating testicular development. These mechanisms are largely unknown, but might involve metabolic hormones, since receptors for these hormones were detected in various cell types in the testes and these hormones affected testicular cell multiplication/differentiation and Leydig cell steroidogenesis (Cailleau et al. 1990, Spiteri-Grech \& Nieschlag 1992, Lin 1995, El-Hefnawy et al. 2000, Wang \& Hardy 2004). Circulating concentrations of metabolic hormones were associated with testes size in developing bulls (Brito et al. 2007a, 2007c), but differences in testes weight in the absence of differences in metabolic hormone concentrations during the peripubertal period in bulls receiving varying levels of nutrition suggested that the gonadotropin-independent mechanisms involved in testicular growth are dependent on previous exposure to gonadotropins during calfhood (Brito et al. $2007 a, 2007 b)$. Therefore, altered gonadotropin secretion during calfhood due to restricted feed may affect mature testes size in bulls.

The objective of the present study was to evaluate the effects of feed restriction during calfhood on serum metabolic hormones, gonadotropins, testosterone, and on sexual development in bulls. We hypothesized that restricted feed during calfhood impairs $\mathrm{LH}$ secretion during the early gonadotropin rise, with long-term effects on age at puberty and testes size that cannot be reverted by improved nutrition during the peripubertal period. We also hypothesized that metabolic hormones are involved in mediating the effects of restricted feed on sexual development.

\section{Materials and Methods}

\section{Bulls and treatments}

Twenty-four Angus and Angus X Charolais bull calves (from Angus and Charolais heifer dams) were weaned at 8 weeks of age ( \pm 12 days) and block randomized (according to genotype and age) into two groups to receive control $(n=8)$ or restricted $(n=16)$ diets from 10 to 26 weeks of age. The control diet consisted of barley silage supplemented with $8.5 \%$ barley grain and $5.5 \%$ canola meal (as fed) and was fed ad libitum. This diet contained $13.2 \%$ crude protein, $1.66 \mathrm{Mcal} / \mathrm{kg}$ net energy of maintenance, and $1.05 \mathrm{Mcal} / \mathrm{kg}$ net energy of gain (dry matter basis). Bulls in the restricted feed group were fed $75 \%$ of the amount consumed by the control group. After 26 weeks of age, bulls in the control group continued to receive the same diet (control/control) and the bulls previously fed the restricted diet received either the same diet as the control group (restricted/control) or a high-nutrition diet (restricted/high; $n=8$ /group). The high-nutrition diet consisted of barley silage supplemented with $22 \%$ barley grain and $15 \%$ canola meal and was fed ad libitum. This diet contained $14.4 \%$ crude protein, $1.75 \mathrm{Mcal} / \mathrm{kg}$ net energy of maintenance, and $1.13 \mathrm{Mcal} / \mathrm{kg}$ net energy of gain. All diets contained $0.5 \%$ molasses and $0.5 \%$ mineral-vitamin premix.

\section{Sexual development}

The bulls were examined every 4 weeks from 14 to 70 weeks of age. Body weight was recorded (starting at 10 weeks of age) and backfat was measured between the 12th and 13th ribs over the longissimus muscle using an A-mode ultrasound (Krautkramer USK 7; Krautkramer Inc., Lewistown, PA, USA). Scrotal circumference was determined with a Coulter Scrotal Tape (Trueman Manufacturing; Edmonton, AB, Canada). The width and length of the testes were measured with calipers and paired testes volume was calculated using a formula (volume $=0.5236 \times$ length $\times$ width $^{2}$; Bailey et al. 1998). To determine age at puberty, attempts to collect semen (by electroejaculation) were initiated once scrotal circumference (SC) reached $26 \mathrm{~cm}$ and were done at 2 -week intervals. Sperm concentration was determined with a hemocytometer and the percentage of progressively motile sperm was estimated with phase contrast microscopy under $400 \times$ magnification. Puberty was defined as an ejaculate containing $\geq 50$ million spermatozoa with $\geq 10 \%$ motile spermatozoa (Wolf et al. 1965). Bulls were sent to slaughter at 70 weeks of age and the testes were recovered and weighed.

\section{Blood sampling and RIA}

During the period of feed restriction, eight bulls were randomly chosen from the restricted feed group for blood sampling. Intensive blood sampling (sampling every $15 \mathrm{~min}$ for $10 \mathrm{~h}$ ) was performed every 4 weeks from 14 to 34 weeks of age. Gonadotropin-releasing hormone (Fertagyl; Intervet Canada Ltd., Whitby, ON, Canada) was administered (0.04 $\mu \mathrm{g} / \mathrm{kg}$, i.v.) after the first $10 \mathrm{~h}$ and blood samples were collected every $15 \mathrm{~min}$ for another $90 \mathrm{~min}$. Additionally, single blood samples were collected before feeding every 4 weeks until 66 weeks of 
age. Blood samples were allowed to clot at room temperature overnight and centrifuged to separate serum, which was stored at $-20{ }^{\circ} \mathrm{C}$ before analysis. Serum concentrations of leptin, insulin, GH, IGF-I, follicle-stimulating hormone $(\mathrm{FSH})$, and testosterone were determined in pooled samples from intensive samplings. LH concentrations were determined in serum samples obtained during the entire intensive sampling period, including after $\mathrm{GnRH}$ treatment. FSH and testosterone concentrations were also determined in serum samples obtained after GnRH treatment. Serum $\mathrm{GH}$ concentrations were determined only until 34 weeks of age. Serum concentrations of leptin, insulin, GH, IGF-I, LH, and FSH were determined by double-antibody RIA, whereas testosterone concentrations were determined by solid-phase RIA using a commercial kit. Tracer leptin was labeled using iodo-gen (Ehrhardt et al. 2000), whereas other tracer hormones were labeled with ${ }^{125}$ I by the Chloramine-T method (Greenwood et al. 1963). Intra- and inter-assay CVs were $<10 \%$ for all hormones.

Purified recombinant bovine leptin (Ehrhardt et al. 2000) was used for preparation of standards and for tracer labeling. Leptin concentrations were determined using rabbit bovine-leptin antiserum, as previously described in cattle (Ehrhardt et al. 2000); the sensitivity of the assay was $0.1 \mathrm{ng} / \mathrm{ml}$. Insulin, GH, and IGF-I concentrations were determined as previously described in ruminants (Van Kessel et al. 1990). Purified recombinant bovine insulin (Lilly Research Laboratories, Indianapolis, IN, USA) was used for the preparation of standards and for tracer labeling. Insulin concentrations were determined using guinea pig bovine-insulin antiserum (Rutter \& Manns 1987); the sensitivity of the assay was $0.1 \mathrm{ng} / \mathrm{ml}$. Purified recombinant bovine $\mathrm{GH}$ AFP-11182B (National Hormone \& Pituitary Program (NHPP); Torrance, CA, USA) was used for the preparation of standards and for tracer labeling. $\mathrm{GH}$ concentrations were determined using monkey bovine$\mathrm{GH}$ antiserum (Anti-bGH AFPB55; NHPP); the sensitivity of the assay was $0.05 \mathrm{ng} / \mathrm{ml}$. Purified recombinant human IGF-I (Ciba Geigy Animal Health, St Aubin, Switzerland) was used for the preparation of standards and for tracer labeling. IGF-I concentrations were determined using mouse human-IGF-I MAB (Kerr et al. 1990). Samples were submitted to acid-ethanol $(87.5 \%$ ethanol, $12.5 \% 2 \mathrm{~mol} \mathrm{HCl} ; \mathrm{v} / \mathrm{v}$ ) extraction prior to analysis; the sensitivity of the assay was $1.0 \mathrm{ng} / \mathrm{ml}$.

Concentrations of gonadotropins and testosterone were determined as previously described in bulls (Evans et al. 1995). LH NIH-bLH-B4 (NHPP) was used for the preparation of standards and USDA-bLH-I-1 (NHPP) was used for tracer labeling. LH concentrations were determined using rabbit bovine-LH antiserum (Rawlings etal. 1984); the sensitivity of the assay was $0.05 \mathrm{ng} / \mathrm{ml}$. FSH USDA-bFSH-I-1 (NHPP) was used for the preparation of standards and AFP-5332B (NHPP) was used for tracer labeling. FSH concentrations were determined using rabbit ovine-FSH antiserum (NIDDK-anti-oFSH-1; NHPP); the sensitivity of the assay was $0.1 \mathrm{ng} / \mathrm{ml}$. Testosterone concentrations were determined using a total testosterone RIA kit (Diagnostic Products Corporation, Los Angeles, CA, USA), but testosterone standards were prepared with purified hormone (Sigma Chemical Co.); the sensitivity of the assay was $0.04 \mathrm{ng} / \mathrm{ml}$.

\section{Statistical analyses}

Characteristics of $\mathrm{LH}$ secretion were determined with the PC-pulsar software (J Gitzen and V Ramirez, University of Illinois, Chicago, IL, USA) and included pulse frequency and amplitude, total secretion (area under the curve), and basal, mean, and peak concentrations. Mean concentration and total secretion of $\mathrm{LH}, \mathrm{FSH}$, and testosterone after $\mathrm{GnRH}$ challenge were also evaluated. Statistical analyses were conducted using Statistical Analysis System (SAS Institute; Cary, NC, USA) and Statistix (Analytical Software; Tallahassee, FL, USA). Analysis was divided into two periods; period 1 was the period of feed restriction (10-26 weeks of age) and period 2 was the period after feed restriction (30-66 weeks of age). Mixed model analysis with Tukey's test was used to determine and locate the effects of nutrition (restricted and control during period 1; control/control, restricted/control, and restricted/high during period 2), age, and the nutrition-by-age interaction on body weight, backfat, SC, paired testes volume, and serum hormone concentrations. The covariate structure that best fitted each end point was used (Littell et al. 1998). One-way ANOVA (and an LSD test) was used to detect and locate the effects of nutrition on age at puberty and paired testes weight.

\section{Results}

Body weight at 10 weeks of age was not different between restricted and control groups $(108.0 \pm 2.3 \mathrm{~kg}$; mean \pm S.E.M). During period 1, there were effects of nutrition, age, and a nutrition-by-age interaction $(P<0.05)$ on body weight, SC, and paired testes volume. There were also effects of nutrition and age on backfat $(P<0.001$; Fig. 1$)$. Body weight, backfat, SC, and paired testes volume increased continuously with age in all groups; overall, these were lower in bulls in the restricted feed group than in the control group. Although there were significant nutrition-by-age interactions, there were no significant differences between groups within age in body weight and SC. There were effects of age and nutrition-by-age interactions $(P<0.05)$ on body weight, backfat, SC, and paired testes volume during period 2 (Fig. 1). Body weight, SC, and paired testes volume increased continuously with age in all groups, whereas backfat increased until 58, 62, and 66 weeks of age in control/control, restricted/control, and restricted/high 

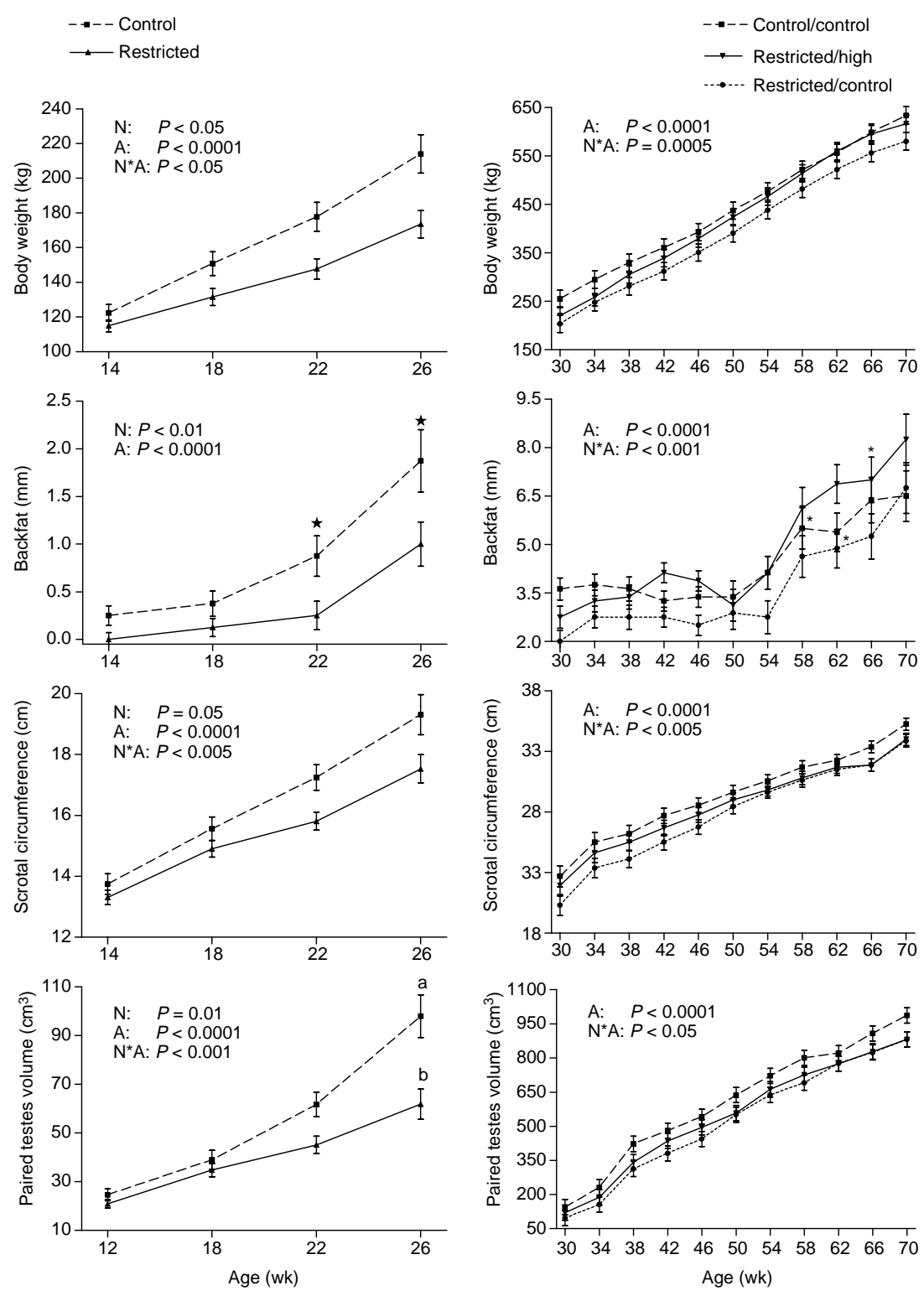

Period 1

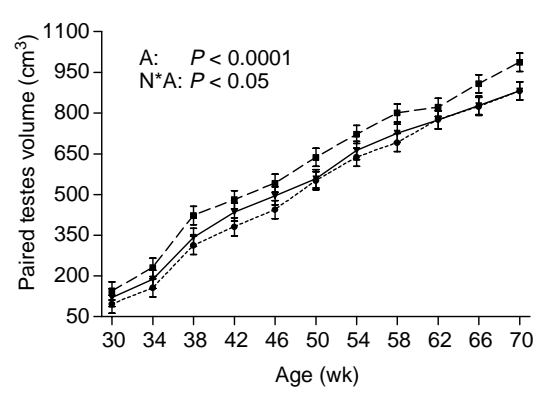

Period 2
Figure 1 Mean ( \pm S.E.M.) body weight, backfat, scrotal circumference (SC), and paired testes volume (PTV) in bulls receiving control nutrition or restricted feed ( $n=8 /$ group) from 10 to 26 weeks of age (period 1 ) and receiving control or high nutrition (control/control, restricted/high, and restricted/control; $n=8 /$ group) after the period of feed restriction (period 2). Body weight, SC, and paired testes volume increased $(P<0.05)$ continuously with age. $N$, nutrition effect; $A$, age effect; $N^{*} A$, nutrition-by-age interaction effect. $\star$ Overall changes $(P<0.05)$ with age. ${ }^{\mathrm{a}, \mathrm{b}}$ Differences $(P<0.05)$ between groups within age. ${ }^{*}$ Changes $(P<0.05)$ with age within group. nutrition groups respectively; there were no significant differences between groups within age.

There were age effects $(P<0.0001)$ on serum leptin and insulin concentrations, and effects of nutrition, age, and a nutrition-by-age interaction $(P<0.01)$ on IGF-I concentrations during period 1 (Fig. 2). Serum leptin and insulin concentrations increased $(P<0.05)$ after 18 and 26 weeks of age respectively. Serum IGF-I concentrations remained unchanged in bulls in the restricted feed group and IGF-I concentrations were lower $(P<0.05)$ in bulls in this group than in those in the control group after 18 weeks of age. There was also an age effect $(P<0.01)$ on serum $\mathrm{GH}$ concentrations during period 1; concentrations decreased from $\sim 10 \mathrm{ng} / \mathrm{ml}$ between 14 and 22 weeks, to $\sim 7 \mathrm{ng} / \mathrm{ml}$ at 26 weeks of age (data not shown). There were age and nutrition by age effects $(P<0.01)$ on serum leptin, insulin, and IGF-I concentrations, and nutrition effects on insulin and IGF-I concentrations during period 2 (Fig. 2). Leptin concentrations increased in the restricted/high and control/control nutrition groups, but did not change significantly in the restricted/control nutrition group. Bulls in the restricted/high nutrition group had a more sustained increase in insulin concentrations than bulls in the other two groups. In the restricted/control and restricted/high nutrition groups, serum IGF-I concentrations increased until 54 weeks of age and decreased thereafter. Overall, bulls in the restricted/high nutrition group had greater $(P \leq 0.07)$ insulin concentrations than those in the other two groups, and greater $(P<0.05)$ IGF-I concentrations than those in the restricted/control nutrition group. Serum $\mathrm{GH}$ concentrations were not 

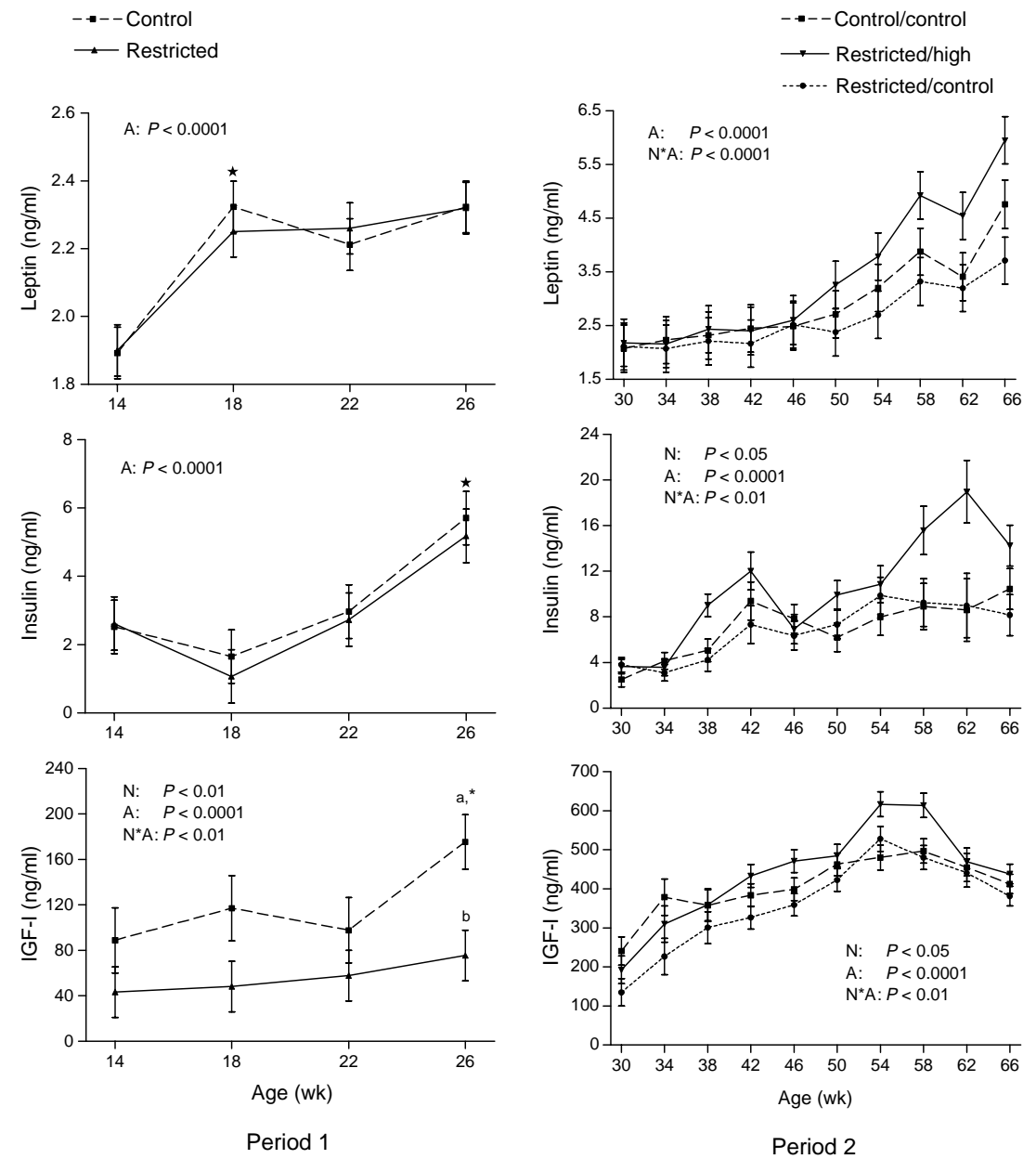

Figure 2 Mean ( \pm s.E.m.) serum leptin, insulin, and IGF-I concentrations in bulls receiving control nutrition or restricted feed ( $n=8$ /group) from 10 to 26 weeks of age (period 1 ) and receiving control or high nutrition (control/control, restricted/high, and restricted/control; $n=8 /$ group) after the period of feed restriction (period 2). N, nutrition effect; $A$, age effect; $N^{*} A$, nutrition-by-age interaction effect. ${ }^{\star}$ Overall changes $(P<0.05)$ with age. ${ }^{\mathrm{a}, \mathrm{b}}$ Differences $(P<0.05)$ between groups within age. ${ }^{*}$ Changes $(P<0.05)$ with age within group. affected by nutrition or age after period 1 (concentrations from 30 to 34 weeks of age were $\sim 8 \mathrm{ng} / \mathrm{ml}$; data not shown).

There were nutrition effects $(P \leq 0.07)$ on $\mathrm{LH}$ pulse frequency, peak concentration, and total secretion, and age effects $(P<0.005)$ on LH pulse frequency and total secretion during period 1 (Fig. 3). Overall, LH pulse frequency, peak concentration, and total secretion were lower in bulls in the restricted feed group than in those in the control group and LH pulse frequency and total secretion decreased $(P<0.05)$ after 22 weeks of age. There was an age effect $(P<0.01)$ on LH total secretion during period 2 (Fig. 3); total secretion increased from 30 to 34 weeks of age. Neither nutrition nor age affected LH basal concentrations or LH pulse amplitude during periods 1 and 2 (data not shown).

There were nutrition effects $(P<0.05)$ on mean serum $\mathrm{LH}$ and testosterone concentrations and age effects $(P<0.005)$ on mean serum $\mathrm{LH}, \mathrm{FSH}$, and testosterone concentrations during period 1 (Fig. 4). Overall, LH and testosterone concentrations were lower $(P<0.05)$ in bulls in the restricted feed group than in bulls in the control group. Gonadotropin concentrations decreased $(P<0.05)$ after 18 weeks of age, whereas testosterone concentrations increased $(P<0.05)$ after this age. There were age effects $(P<0.0005)$ on serum LH, FSH, and testosterone concentrations, and a nutrition-by-age interaction $(P<0.0001)$ on $\mathrm{LH}$ concentrations during period 2 (Fig. 4). Serum LH concentrations increased $(P<0.05)$ at 50 and 66 weeks of age only in bulls in the restricted/high nutrition group. Overall, FSH concentrations increased $(P<0.05)$ after 54 weeks and testosterone concentrations increased $(P<0.05)$ after 38 weeks of age.

There were nutrition and age effects $(P<0.01)$ on mean $\mathrm{LH}$ concentrations and total secretion during period 1 (Fig. 5). Both GnRH-induced mean LH concentrations and total $\mathrm{LH}$ secretion were lower $(P<0.01)$ in bulls in the restricted feed group than in those in the control group. Mean LH concentrations and total secretion increased $(P<$ $0.05)$ at 18 weeks of age. Neither nutrition nor age affected $\mathrm{GnRH}$-induced $\mathrm{LH}$ secretion during period 2 (Fig. 5). There were age effects $(P<0.0001)$ on mean FSH concentrations and total secretion after $\mathrm{GnRH}$ treatment during period 1 (both decreased after 18 weeks of age), but no nutrition or age effect during period 2 (data not shown). 

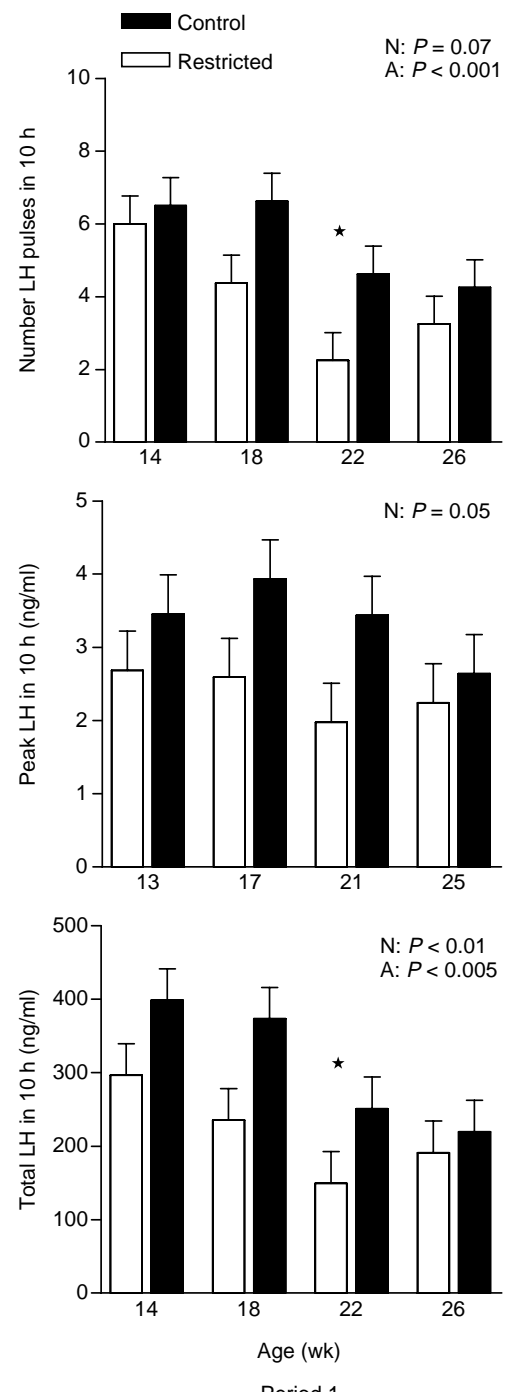
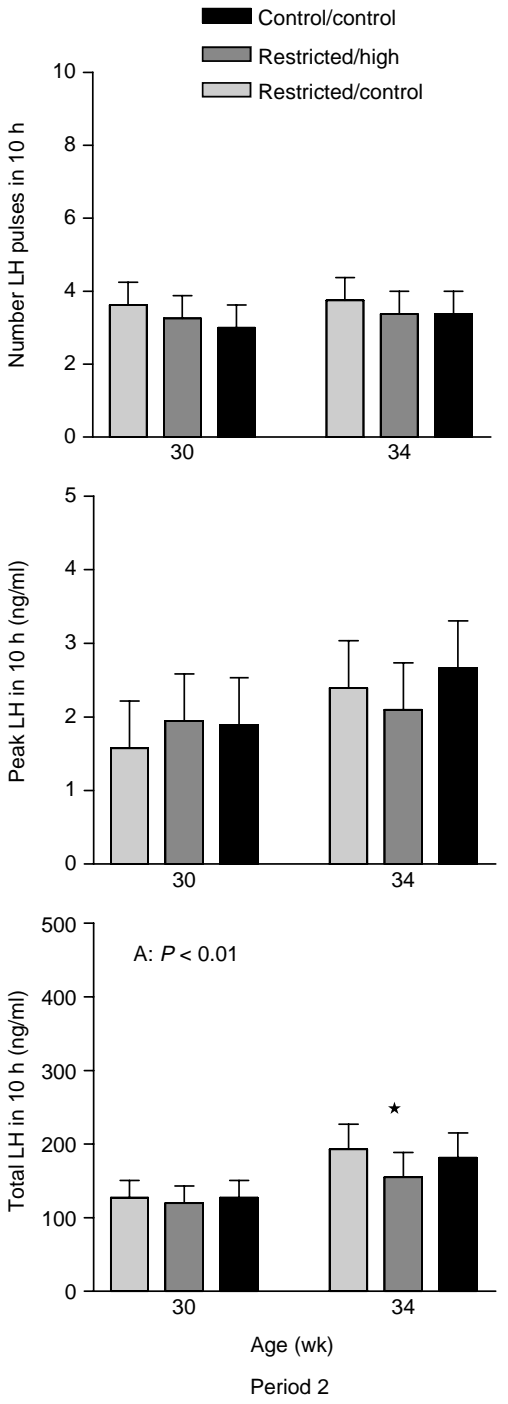

Figure 3 Mean ( \pm S.E.M.) number of LH pulses, serum peak concentration, and total secretion in $10 \mathrm{~h}$ in bulls receiving control nutrition or restricted feed ( $n=8$ /group) from 10 to 26 weeks of age (period 1) and receiving control or high nutrition (control/control, restricted/high, and restricted/control; $n=8$ /group) after the period of feed restriction (period 2). N, nutrition effect; $A$, age effect. ${ }^{\star}$ Overall changes $(P<0.05)$ with age.
There were nutrition and age effects $(P<0.05)$ on mean testosterone concentrations and total secretion after $\mathrm{GnRH}$ treatment during period 1 (Fig. 6). Overall, GnRH-induced mean testosterone concentrations and total secretion increased $(P<0.05)$ with age and was lower $(P<0.05)$ in bulls in the restricted feed group than in those in the control group. There was an effect of age and a nutrition-by-age interaction $(P<0.005)$ on mean testosterone concentrations and total secretion after $\mathrm{GnRH}$ treatment during period 2 (Fig. 6). $\mathrm{GnRH}$-induced mean testosterone concentrations and total secretion increased $(P<0.05)$ from 30 to 34 weeks of age only in bulls in the restricted/control group.

Bulls in the control/control nutrition group were younger $(P<0.05)$ at puberty and had greater $(P<0.05)$ paired testes weight at 70 weeks of age than those in the restricted/control nutrition group (292.6 \pm 10.6 vs $330.5 \pm 9.0$ days and $600.0 \pm 12.1$ vs $528.3 \pm 26.2 \mathrm{~g}$ respectively; mean \pm S.E.M). Age at puberty and paired testes weight for bulls in the restricted/high nutrition group were intermediate $(312.7 \pm 12.5$ days and $552.9 \pm$ 24.9 g respectively).

\section{Discussion}

Bulls that received restricted feed during calfhood were older at puberty and had lighter testes at 70 weeks of age. Therefore, restricted feed during calfhood adversely affected sexual development and these effects were not compensated by nutritional supplementation during the peripubertal period. The adverse effects of restricted feed on sexual development were exerted on all levels of the hypothalamus-pituitary-gonad axis and may have been mediated by IGF-I.

Secretion of LH was reduced during the period of the early gonadotropin rise during calfhood in bulls receiving restricted feed. Puberty was delayed in these bulls, despite the lack of major differences in metabolic hormones, gonadotropins, or testosterone concentrations after diets were changed in the peripubertal 

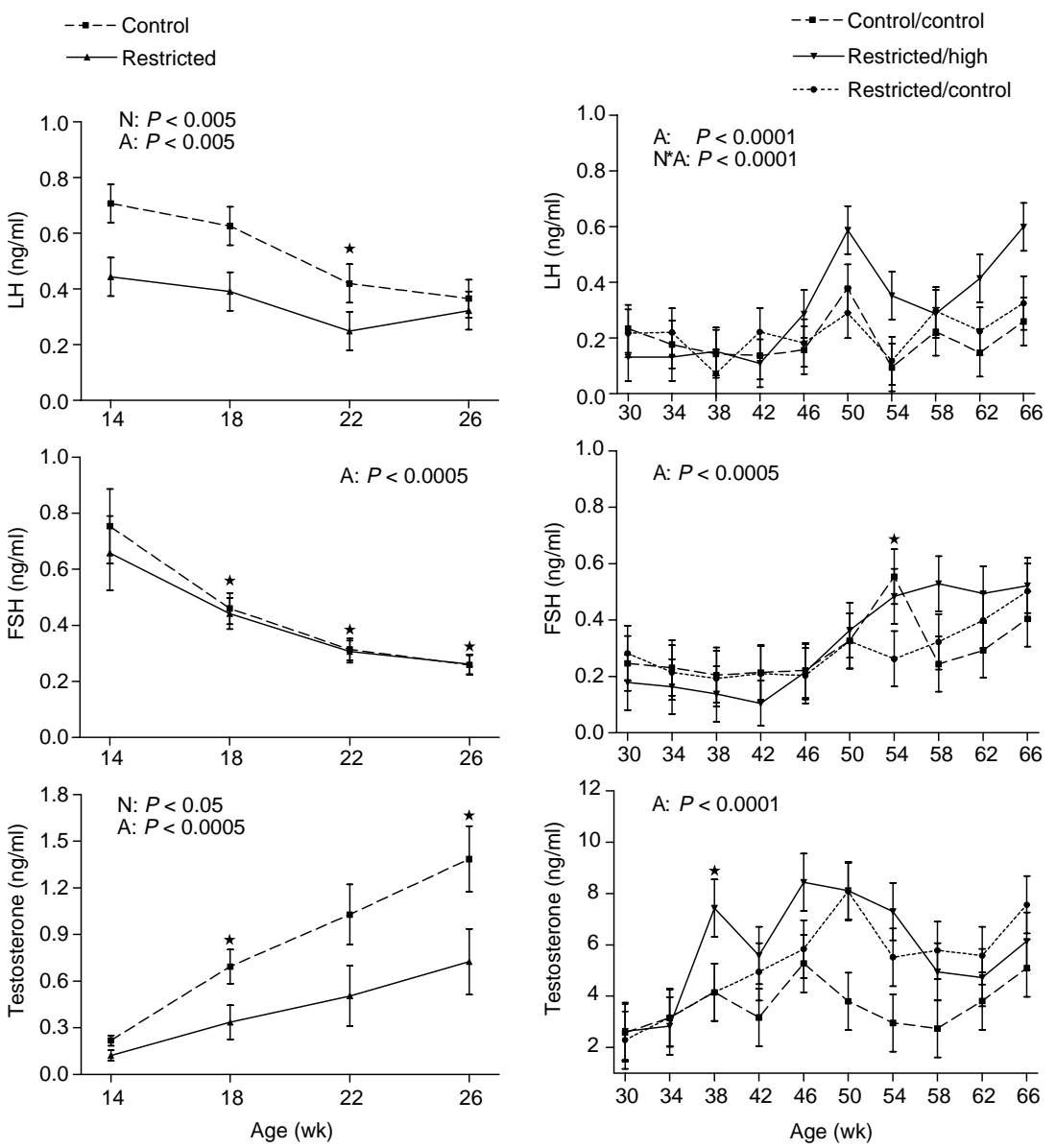

Period 1

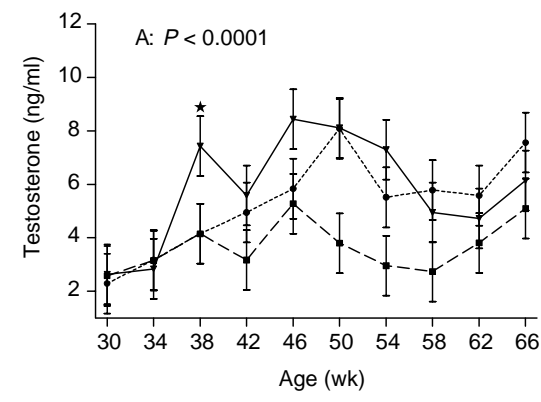

Period 2
Figure 4 Mean ( \pm s.E.M.) serum LH, FSH, and testosterone concentrations in bulls receiving control nutrition or restricted feed ( $n=8$ /group) from 10 to 26 weeks of age (period 1 ) and receiving control or high nutrition (control/control, restricted/high, and restricted/control; $n=8$ /group) after the period of feed restriction (period 2). $\mathrm{N}$, nutrition effect; $\mathrm{A}$, age effect; $\mathrm{N}^{*} \mathrm{~A}$, nutrition-by-age interaction effect. ${ }^{\star}$ Overall changes $(P<0.05)$ with age. ${ }^{*}$ Changes $(P<0.05)$ with age within group. period. This observation supported the hypothesis that the pattern of $\mathrm{LH}$ secretion during the early gonadotropin rise during calfhood is the main determinant of age of puberty in bulls. In that regard, late-maturing bulls had lower LH secretion than early maturing bulls during the early gonadotropin rise (Evans et al. 1995, Aravindakshan et al. 2000). Moreover, bulls receiving a low-nutrition diet had reduced LH pulse frequency during the early gonadotropin rise and were older at puberty than those receiving medium or high nutrition (Brito et al. 2007a).

Although differences in LH pulse frequency observed between control and restricted feed groups during calfhood were not significant at $P<0.05$ level, an important consideration is that intensive samplings were performed for only $10 \mathrm{~h}$ due to practical constraints. It seems reasonable to assume that differences in LH secretion would only increase had samplings been performed for longer periods. Therefore, the tendency $(P=0.07)$ of greater LH pulse frequency in the control group should be considered of biological significance. Lower LH pulse frequency in bulls receiving restricted feed indicated that nutrition affected the $\mathrm{GnRH}$ pulse generator in the hypothalamus during the period of the early gonadotropin rise. The $\mathrm{GnRH}$ pulse generator is the primary regulator of reproductive function and is the primary locus of inhibition by restricted nutrition in males and females (Schneider 2004).

Metabolic signals, hormonal mediators and modulators, and neuropeptides are involved in an intricate mechanism by which circulating (peripheral) signals are translated within the brain and ultimately regulate the function of GnRH neurons (Blache et al. 2003, Schneider 2004). Although temporal associations do not necessarily reflect cause-and-effect relationships, decreased IGF-I concentrations during calfhood in bulls receiving restricted feed suggested that IGF-I may serve as a signal translating nutritional status to the hypothalamus, since the differences in IGF-I concentrations during calfhood coincided with differences in $\mathrm{LH}$ pulse secretion. In support of this possible regulatory role, IGF-I receptors were present in the brain in rodents and in immortalized GnRH-secreting neurons (GTI-7 cell line), GnRH neurons expressed IGF-I receptors, and IGF-I stimulated GnRH secretion from GTI-7 cells and female rat brain in vitro (Hiney et al. 1991, Anderson et al. 1999, Miller \& Gore 2001, Daftary \& Gore 2004). Control of GnRH secretion by IGF-I may also involve reducing 

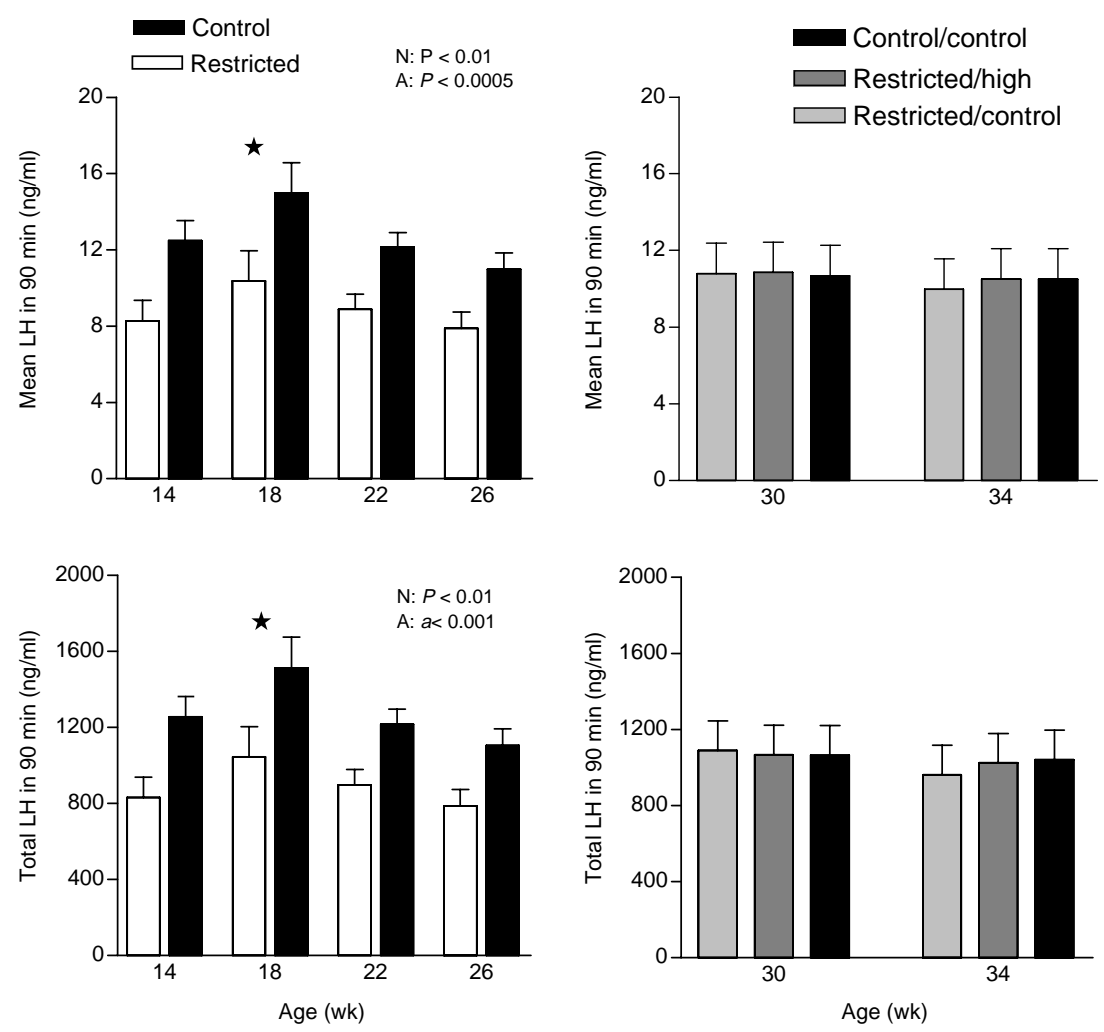

Period 1

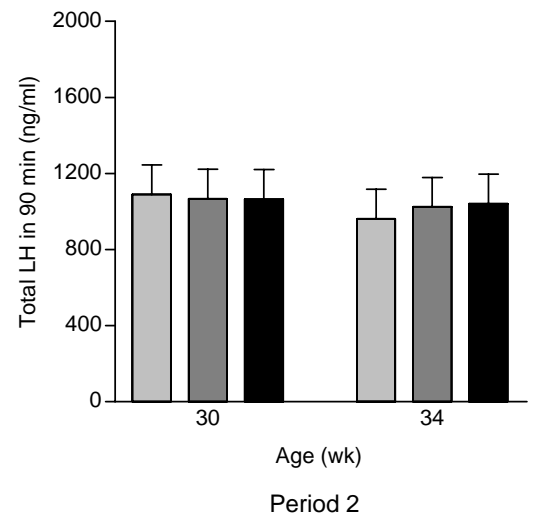

Figure 5 Mean ( \pm s.E.M.) serum LH concentration and total secretion after $\mathrm{GnRH}$ challenge $(0.04 \mu \mathrm{g} / \mathrm{kg}$, i.v. $)$ in bulls receiving control nutrition or restricted feed ( $n=8$ /group) from 10 to 26 weeks of age (period 1) and control or high nutrition (control/control, restricted/high, and restricted/control; $n=8$ /group) after the period of feed restriction (period 2 ). $N$, nutrition effect; $A$, age effect. ${ }^{\star}$ Overall changes $(P<0.05)$ with age. hypothalamic hypersensitivity to negative steroid feedback during pubertal development (Wilson 1995). Moreover, in previous studies, $\mathrm{LH}$ secretion was also reduced concomitantly with low serum IGF-I concentrations in bulls receiving low nutrition during calfhood, whereas LH secretion was augmented in bulls receiving high nutrition concomitantly with high serum IGF-I concentrations (Brito et al. 2007a, 2007b).

The suppression of LH secretion in the present study was more pronounced than in a previous study conducted to evaluate the effects of diet on gonadotropins secretion in young bulls (Brito et al. 2007a). In that study, low nutrition during calfhood resulted in reduced $\mathrm{LH}$ pulse frequency, but mean and peak $\mathrm{LH}$ concentrations and total $\mathrm{LH}$ secretion were not affected as in the present study. Moreover, in contrast to the previous study, $\mathrm{GnRH}$-stimulated $\mathrm{LH}$ secretion was reduced in bulls receiving restricted feed in the present study, indicating that restricted feed also affected pituitary function. One explanation for the apparent contrast between these studies is the difference in experimental design. In the previous study, the group of bulls receiving low nutrition received a diet of plain forage (no concentrate), but intake was not restricted in contrast with the present experiment (intake was limited in the restricted feed group). Therefore, we inferred that $\mathrm{LH}$ secretion is regulated by not only the availability of nutrients but also by the central center responsible for the sensations of hunger and satiety. The inhibitory effects of limited availability of nutrients on $\mathrm{LH}$ secretion were exerted only on the hypothalamus (Brito et al. 2007a). In contrast, the combination of limited availability of nutrients with the hunger sensation experienced by bulls with restricted intake in the present study affected both hypothalamic and pituitary function, producing much more severe inhibition of $\mathrm{LH}$ secretion. IGF-I receptors were detected in the pituitary and IGF-I stimulates gonadotropin secretion from rat pituitary in vitro (Rosenfeld et al. 1984, Soldani et al. 1995), indicating a possible regulatory role for IGF-I on pituitary function. However, circulating IGF-I concentrations during calfhood in the present study were not substantially different from that observed in the previous study in which low nutrition did not affect pituitary function (Brito et al. 2007a).

Restricted feed did not significantly reduce serum concentrations of leptin, insulin, and $\mathrm{GH}$. The large differences in $\mathrm{LH}$ secretion without differences in concentrations of these metabolic hormones between restricted feed and control groups in the present study supported the notion that these hormones have only a permissive effect on gonadotropin secretion. Feed restriction in ewes decreased $\mathrm{LH}$ secretion concomitantly with decreased leptin and insulin concentrations, but leptin and insulin concentrations returned to control values at the end of the feed restriction period without any rebound in LH secretion (Recabarren et al. 2004). Moreover, differences in leptin, insulin, and $\mathrm{GH}$ 

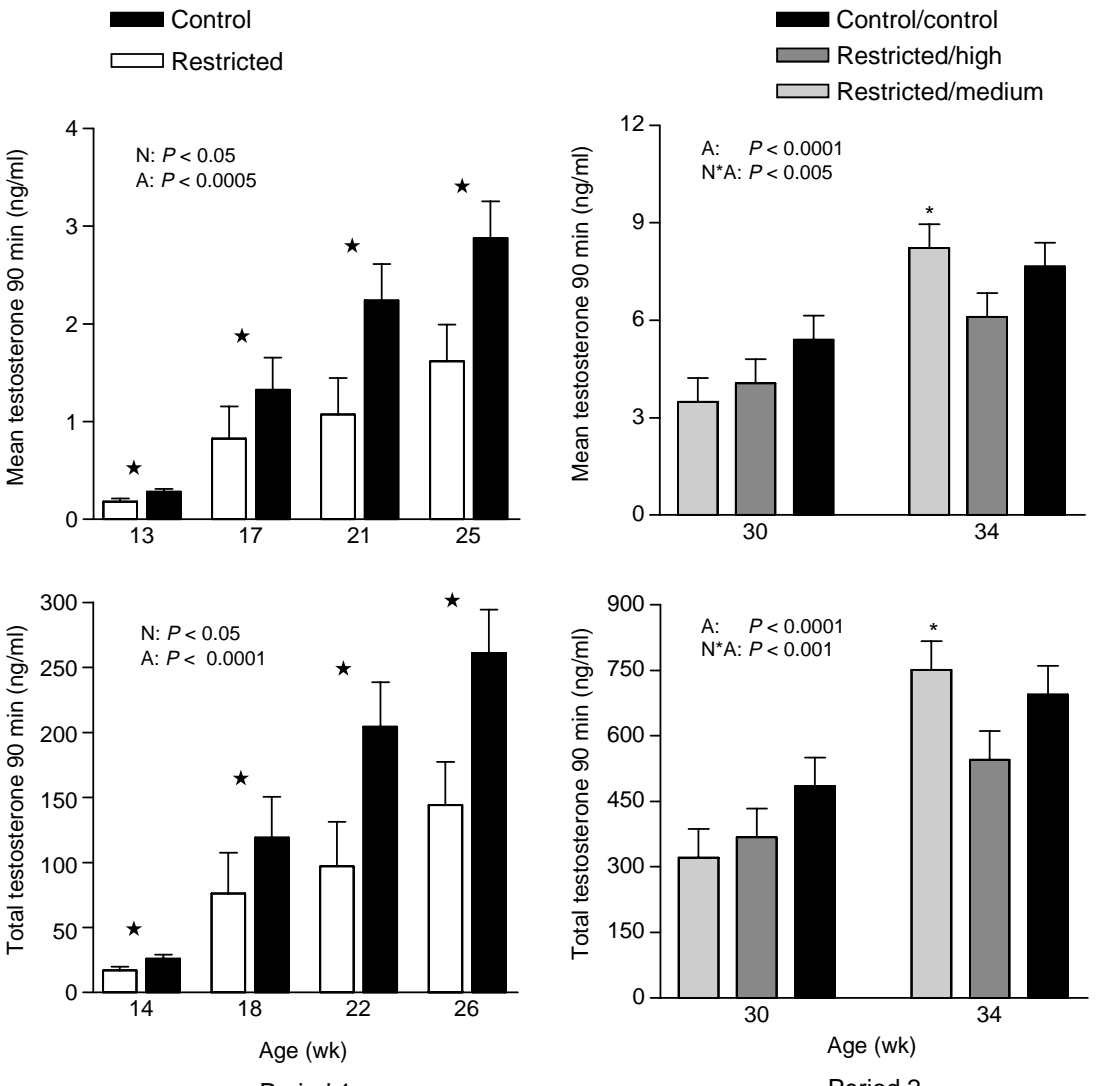

Period 2
Figure 6 Mean ( \pm s.E.M.) serum testosterone concentrations and total secretion after $\mathrm{GnRH}$ challenge $(0.04 \mu \mathrm{g} / \mathrm{kg}$, i.v. $)$ in bulls receiving control nutrition or restricted feed ( $n=8$ /group) from 10 to 26 weeks of age (period 1 ) and receiving control or high nutrition (control/control, restricted/high, and restricted/control; $n=8$ /group) after the period of feed restriction (period 2). $\mathrm{N}$, nutrition effect; $A$, age effect; $N^{*} A$, nutrition-by-age interaction effect. ${ }^{\star}$ Overall changes $(P<0.05)$ with age. ${ }^{*}$ Changes $(P<0.05)$ with age within group. concentrations were not associated with differences in $\mathrm{LH}$ secretion in young bulls receiving either low or high nutrition during calfhood (Brito et al. 2007a, 2007 b). The results of the present experiment indicated that feed intake restricted to $75 \%$ of the normal ad libitum intake resulted in circulating leptin, insulin, and $\mathrm{GH}$ concentrations that were not involved in altering the early gonadotropin rise in young bulls. Therefore, reduced gonadotropin secretion due to reduced concentrations of these metabolic hormones must result from severe undernutrition. Alternatively, short-term mechanisms involving leptin and insulin may also be important, as a drastic decrease in circulating concentrations of these hormones promoted by fasting also inhibited $\mathrm{LH}$ secretion in cattle (Amstalden et al. 2000, 2002).

Restricted feed during calfhood also reduced both physiological and GnRH-stimulated testosterone secretion. Therefore, nutrition also had direct effects on Leydig cell number or function (or both). These effects could be mediated by IGF-I, since receptors have been identified in Leydig cells in several species and IGF-I increased proliferation and differentiation of Leydig cells (Spiteri-Grech \& Nieschlag 1992, Lin 1995). Leydig cell numbers and expression of steroidogenic enzymes were decreased in IGF-I-null mice and IGF-I treatments in combination with LH were necessary for normal Leydig cell development in these animals (Wang \& Hardy 2004).
In vitro, IGF-I up-regulated Leydig cell LH receptors and increased both basal and LH-stimulated testosterone secretion (Spiteri-Grech \& Nieschlag 1992, Lin 1995). Leydig cells also produced IGF-I, indicating the existence of a paracrine/autocrine mechanism of testicular regulation involving the IGF-I system (Rouiller-Fabre et al. 1998). Interestingly, IGF-I stimulated testosterone secretion and testosterone in turn up-regulated IGF-I receptors and IGF-I production by Leydig cells (Cailleau et al. 1990). Therefore, circulating IGF-I may have initially up-regulated testosterone production, which in turn stimulated IGF-I secretion and established a positive feedback loop between IGF-I and testosterone secretion in Leydig cells in peripubertal bulls. In that regard, IGF-I treatment increased gonadal sensitivity to gonadotropins and hastened puberty in female monkeys (Wilson 1998).

In rams, improved nutrition had positive effects on testicular growth that were maintained beyond the period of the gonadotropins rise promoted by improved nutrition (Blache et al. 2002). In bulls, testicular growth rate was maximal during the peripubertal period (6-16 months of age), coincident with decreasing gonadotropin concentrations (Rawlings et al. 1978, Amann \& Walker 1983). These observations indicated the existence of gonadotropin-independent mechanisms regulating testicular development in male ruminants. Circulating metabolic hormones may be involved in regulating testicular growth 
during the peripubertal period in bulls (Brito et al. 2007a, 2007C). However, although circulating concentrations of leptin, insulin, IGF-I, and testosterone after improved nutrition during the peripubertal period in bulls that had received restricted feed where either similar or greater than in control bulls, testes weight at 70 weeks of age was still less in bulls that had received restricted feed. These observations supported the hypothesis that gonadotropinindependent mechanisms of testicular development which may involve metabolic hormones are dependent on previous exposure to gonadotropins. The pattern of $\mathrm{LH}$ secretion during calfhood may 'prime' testicular development and dictate maximum adult testicular size in bulls. Accordingly, suppressing LH secretion with prolonged $\mathrm{GnRH}$ treatment during calfhood reduced paired testes weight at 50 weeks of age (Chandolia et al. 1997a). Moreover, high nutrition during calfhood resulted in either greater $\mathrm{LH}$ pulse frequency or a more sustained increase in pulse frequency during the early gonadotropin rise with greater testes weight at 16 months of age when compared with control nutrition, in the absence of differences in metabolic hormone concentrations during the peripubertal period in bulls (Brito et al. 2007a, 2007b).

In conclusion, restricted feed during calfhood affected sexual development in bulls as a result of adverse effects on every level of the hypothalamus-pituitary-gonad axis. Restricted feed inhibited the hypothalamic GnRH pulse generator, reduced the pituitary response to $\mathrm{GnRH}$, and adversely affected testicular steroidogenesis. Temporal associations indicated that the effects of restricted feed on the HPG axis might be mediated by circulating IGF-I concentrations. Bulls receiving restricted feed had lower LH secretion during calfhood, delayed puberty, and lessened testicular weight at 16 months of age, independent of the increased circulating concentrations of metabolic hormones and testosterone after improved nutrition during the peripubertal period. These observations supported the hypotheses that the pattern of $\mathrm{LH}$ secretion during the early gonadotropin rise during calfhood is the main determinant of age of puberty in bulls and that gonadotropin-independent mechanisms involved in testicular growth during the peripubertal period are affected by previous $\mathrm{LH}$ exposure.

\section{Acknowledgements}

This work was supported by Agriculture and Agri-Food Canada, the Western College of Veterinary Medicine, and the Saskatchewan Agriculture Development Fund. We thank the farm staff of the Lethbridge Research Centre for their care of the bulls and Susan Cook, Charlotte Hampton, and Laura Nauta for their technical assistance. The authors declare that there is no conflict of interest that would prejudice the impartiality of this scientific work.

\section{References}

Amann RP \& Walker OA 1983 Changes in the pituitary-gonadal axis associated with puberty in Holstein bulls. Journal of Animal Science 57 433-442.

Amstalden M, Garcia MR, Williams SW, Stanko RL, Nizielski SE, Morrison CD, Keisler DH \& Williams GL 2000 Leptin gene expression, circulating leptin, and luteinizing hormone pulsatility are acutely responsive to short-term fasting in prepubertal heifers: relationships to circulating insulin and insulin-like growth factor I. Biology of Reproduction 63 127-133.

Amstalden M, Garcia MR, Stanko RL, Nizielski SE, Morrison CD, Keisler DH \& Williams GL 2002 Central infusion of recombinant ovine leptin normalizes plasma insulin and stimulates a novel hypersecretion of luteinizing hormone after short-term fasting in mature beef cows. Biology of Reproduction 66 1555-1561.

Anderson RA, Zwain IH, Arroyo A, Mellon PL \& Yen SS 1999 The insulin-like growth factor system in the GT1-7 GnRH neuronal cell line. Neuroendocrinology 70 353-359.

Aravindakshan JP, Honaramooz A, Bartlewski PM, Beard AP, Pierson RA \& Rawlings NC 2000 Pattern of gonadotropin secretion and ultrasonographic evaluation of developmental changes in the testis of early and late maturing bull calves. Theriogenology 54 339-354.

Bailey TL, Hudson RS, Powe TA, Riddell MG, Wolfe DF \& Carson RL 1998 Caliper and ultrasonographic measurements of bovine testicles and a mathematical formula for determining testicular volume and weight in vivo. Theriogenology 49 581-594.

Barth AD \& Ominski KH 2000 The relationship between scrotal circumference at weaning and at one year of age in beef bulls. Canadian Veterinary Journal 41 541-546.

Blache D, Adam CL \& Martin GB 2002 The mature male sheep: a model to study the effects of nutrition on the reproductive axis. Reproduction Supplement 59 219-233.

Blache D, Zhang S \& Martin GB 2003 Fertility in male sheep: modulators of the acute effects of nutrition on the reproductive axis of male sheep. Reproduction Supplement 61 387-402.

Brito LF, Barth AD, Rawlings NC, Wilde RE, Crews DH Jr, Mir PS \& Kastelic JP 2007a Effect of nutrition during calfhood and peripubertal period on serum metabolic hormones, gonadotropins and testosterone concentrations, and on sexual development in bulls. Domestic Animal Endocrinology 33 1-18.

Brito LF, Barth AD, Rawlings NC, Wilde RE, Crews DH Jr, Mir PS \& Kastelic JP 2007b Effect of improved nutrition during calfhood on serum metabolic hormones, gonadotropins, and testosterone concentrations, and on testicular development in bulls. Domestic Animal Endocrinology (In Press).

Brito LF, Barth AD, Rawlings NC, Wilde RE, Crews DH Jr, Mir PS \& Kastelic JP 2007c Circulating metabolic hormones during the peripubertal period and their association with testicular development in bulls. Reproduction in Domestic Animals (In Press).

Cailleau J, Vermeire S \& Verhoeven G 1990 Independent control of the production of insulin-like growth factor I and its binding protein by cultured testicular cells. Molecular and Cellular Endocrinology 69 79-89.

Chandolia RK, Evans AC \& Rawlings NC 1997a Effect of inhibition of increased gonadotrophin secretion before 20 weeks of age in bull calves on testicular development. Journal of Reproduction and Fertility 109 65-71.

Chandolia RK, Honaramooz A, Bartlewski PM, Beard AP \& Rawlings NC $1997 b$ Effects of treatment with LH releasing hormone before the early increase in LH secretion on endocrine and reproductive development in bull calves. Journal of Reproduction and Fertility 111 41-50.

Coulter GH 1986 Puberty and postpubertal development of beef bulls. In Current Therapy in Theriogenology, 1 edn, pp 142-148. Ed. AD Morrow. Philadelphia: Saunders.

Daftary SS \& Gore AC 2004 The hypothalamic insulin-like growth factor-1 receptor and its relationship to gonadotropin-releasing hormones neurones during postnatal development. Journal of Neuroendocrinology 16 160-169. 
Ehrhardt R, Slepetis R, Siegal-Willott J, Van Amburgh M, Bell A \& Boisclair Y 2000 Development of a specific radioimmunoassay to measure physiological changes of circulating leptin in cattle and sheep. Journal of Endocrinology 166 519-528.

El-Hefnawy T, Ioffe S \& Dym M 2000 Expression of the leptin receptor during germ cell development in the mouse testis. Endocrinology $1412624-2630$

Evans A, Davies F, Nasser L, Bowman P \& Rawlings N 1995 Differences in early patterns of gonadotrophin secretion between early and late maturing bulls, and changes in semen characteristics at puberty. Theriogenology 43 569-578.

Greenwood F, Hunter W \& Glover J 1963 The preparation of ${ }^{131} \mathrm{I}$ labelled human growth hormone of high specific radioactivity. Biochemical Journal 89 114-123.

Hiney JK, Ojeda SR \& Dees WL 1991 Insulin-like growth factor I: a possible metabolic signal involved in the regulation of female puberty. Neuroendocrinology 54 420-423.

Kerr DE, Laarveld B \& Manns JG 1990 Effects of passive immunization of growing guinea-pigs with an insulin-like growth factor-I monoclonal antibody. Journal of Endocrinology 124 403-415.

Van Kessel AG, Korchinski RS, Hampton CH \& Laarveld B 1990 Effect of immunization against somatostatin in the pregnant ewe on growth and endocrine status of the neonatal lamb. Domestic Animal Endocrinology 7 217-227.

Lin T 1995 Regulation of Leydig cell function by insulin-like growth factor-I and binding proteins. Journal of Andrology 16 193-196.

Littell RC, Henry PR \& Ammerman CB 1998 Statistical analysis of repeated measures data using SAS procedures. Journal of Animal Science 76 1216-1231.

Miller BH \& Gore AC 2001 Alterations in hypothalamic insulin-like growth factor-I and its associations with gonadotropin releasing hormone neurones during reproductive development and ageing. Journal of Neuroendocrinology 13 728-736.

Rawlings NC, Fletcher PW, Henricks DM \& Hill JR 1978 Plasma luteinizing hormone (LH) and testosterone levels during sexual maturation in beef bull calves. Biology of Reproduction 19 1108-1112.

Rawlings NC, Jeffcoate IA \& Rieger DL 1984 The influence of estradiol$17 \beta$ and progesterone on peripheral serum concentrations of luteinizing hormone and follicle stimulating hormone in the ovariectomized ewe. Theriogenology 22 473-488.
Recabarren SE, Lobos A, Torres V, Oyarzo R \& Sir-Petermann T 2004 Secretory patterns of leptin and luteinizing hormone in food-restricted young female sheep. Biological Research 37 371-384.

Rosenfeld RG, Ceda G, Wilson DM, Dollar LA \& Hoffman AR 1984 Characterization of high affinity receptors for insulin-like growth factors I and II on rat anterior pituitary cells. Endocrinology 114 1571-1575.

Rouiller-Fabre V, Lecref L, Gautier C, Saez JM \& Habert R 1998 Expression and effect of insulin-like growth factor I on rat fetal Leydig cell function and differentiation. Endocrinology 139 2926-2934.

Rutter LM \& Manns JG 1987 Hypoglycemia alters pulsatile luteinizing hormone secretion in the postpartum beef cow. Journal of Animal Science 64 479-488.

Schneider JE 2004 Energy balance and reproduction. Physiology and Behavior 81 289-317.

Soldani R, Cagnacci A, Paoletti A, Yen S \& Melis G 1995 Modulation of anterior pituitary luteinizing hormone response to gonadotropinreleasing hormone by insulin-like growth factor I in vitro. Fertility and Sterility 64 634-637.

Spiteri-Grech J \& Nieschlag E 1992 The role of growth hormone and insulin-like growth factor I in the regulation of male reproductive function. Hormone Research 38 (Suppl 1) 22-27.

Wang G \& Hardy MP 2004 Development of leydig cells in the insulinlike growth factor-I (igf-I) knockout mouse: effects of igf-I replacement and gonadotropic stimulation. Biology of Reproduction 70 632-639.

Wilson ME 1995 IGF-I administration advances the decrease in hypersensitivity to oestradiol negative feedback inhibition of serum $\mathrm{LH}$ in adolescent female rhesus monkeys. Journal of Endocrinology 145 121-130.

Wilson ME 1998 Premature elevation in serum insulin-like growth factor-I advances first ovulation in rhesus monkeys. Journal of Endocrinology 158 247-257.

Wolf FR, Almquist JO \& Hale EB 1965 Prepuberal behavior and puberal characteristics of beef bulls on high nutrient allowance. Journal of Animal Science 24 761-765.

Received 4 December 2006

First decision 15 January 2007

Revised manuscript received 26 February 2007

Accepted 6 March 2007 